\title{
Sexo, Justiça e Direito: A propósito de Novas Cartas Portuguesas
}

\author{
Maria do Céu da Cunha Rego \\ Centro Interdisciplinar de Estudos de Género, CIEG - ISCSP
}

Resumo: 0 artigo procura demonstrar como Novas Cartas Portuguesas fixam, com extraordinário brilho literário, um diagnóstico acutilante sobre os papéis sociais de género, a antecipar em cerca de 20 anos os resultados da IV Conferência Mundial sobre as Mulheres, em Pequim - 1995 - e a Plataforma de Ação para a promoção da igualdade de facto entre mulheres e homens, cuja atualidade se mantem. Sustenta-se que o reconhecimento de direitos e deveres novos no sistema internacional dos Direitos Humanos - direito à igualdade substantiva de homens e mulheres tanto na esfera pública como na esfera privada, incluindo o direito ao cuidado e o dever de cuidar em paridade de familiares dependentes e das tarefas domésticas, direitos autónomos, intransmissíveis e de gozo obrigatório para os homens quando são pais - constituem passo decisivo para a concretização da justiça de género, que está na base de uma organização social democrática que pretenda atingir os Objetivos do Desenvolvimento Sustentável.

Palavras-chave: sexo, Justiça, Direito da Igualdade entre mulheres e homens, papéis sociais de género, cuidado, Novas Cartas Portuguesas, novos direitos, novos deveres

\footnotetext{
Abstract: The article pretends to show how New Portuguese Letters fix, with extraordinary literary shine, a sharp diagnosis on social gender roles, anticipating in about 20 years the results of the Fourth World Conference on Women in Beijing - 1995 - and the Platform for Action then agreed to promote de facto gender equality, which actuality remains. The article supports the recognition of new rights and duties in the international system of Human Rights - right to substantive gender equality as in the public as in the private spheres, including care as a right and as a duty towards family dependents to share in parity, right to parity in domestic tasks, autonomous, non-transferable and mandatory rights for fathers - is a critical step to de facto 
gender justice, the pillar of a democratic social organization willing to achieve the Objectives for Sustainable Development.

Keywords: sex, Justice, Gender Equality Law, social gender roles, care, New Portuguese Letters, new rights, new duties

Tenho pelas autoras de Novas Cartas Portuguesas um enorme respeito e muita gratidão: pelo seu talento literário, pela palavra exacta, pela análise e questionamento da realidade, pelo diagnóstico preciso da situação universal de mulheres e homens - disseram tudo e foram além do que a comunidade internacional reconheceu e recomendou em Pequim mais de 20 anos depois, ${ }^{1}$ pelo que ajudaram a entender a vida, pelo que fizerem e fazem reflectir e mudar, pelo que acrescentaram em potencial de concretização do bem comum, pela força e pelo empoderamento que deram às mulheres e à sua esperança, pela coragem de usar a liberdade de pensamento e de acção em tempos de autocracia e em País fortemente marcado pela desigualdade legal de homens e mulheres, pela inspiração que foram e continuam a ser para quem persiste na busca de contributos para uma organização social equilibrada.

\section{A propósito de Novas Cartas Portuguesas, tratemos de SEXO.}

No princípio era o sexo. ${ }^{2}$ Os sexos e a sua diferença. Para o que conta aqui, a diferença é o útero, um exclusivo das mulheres. “(...) e mulher e marido juntam as cabeças ao serão olhando o corpo que cresce emprenhado, e porque o homem procura seu útero, e porque no corpo da mulher se gera fruto dito do homem e da sociedade" (Barreno / Horta / Costa 2010: 284).

Um poder exclusivo delas. "Lhes daremos filhos, sim, mas em gosto gerados e paridos nossos" (idem: 10). 
A imortalidade oferecida pela natureza. “(...) - filho riqueza, mão de obra, imortalidade em outro - corpo de mulher com seu sangue e ciclos e que se rasga noutro corpo filho, mistério de vida e de morte, (...)” (idem: 81).

A maternidade certa. A paternidade incerta. Em Portugal, diz o povo: 'Filhos da minha filha, meus netos são, filhos do meu filho, serão ou não'.

A paternidade muitas vezes negada. Por poder delas, homens sem descendência, sem o amor de filhos, sem futuro.

Dizem-me que sou estéril, disso me culpando meu marido como se de pecado me acusasse, jamais pensando ele a mansa, dolorosa, mas total alegria que isso me dá. (idem: 135)

Pois se nem eu, senhora, vos arranquei o segredo que ocultais sedenta de raiva contra mim, quanto a Mariana que pressinto de meu sangue (...) que chantagem sois vós hoje que exerceis sobre mim, (...) condenando-me para sempre (...) a silenciar o amor a minha filha (...) se jamais me foi permitido, sequer, falar a Mariana (...). Se assim me castigais até ao sangue por vos haver humilhado um dia, deixai em paz nossa filha, que culpa não se lhe conhece senão a de se permitir ser infeliz por vossas mãos! (idem: 184)

E é o altíssimo preço desse poder imenso, involuntário e imutável porque vem da natureza, mas objectivamente assimétrico face aos homens, que as mulheres continuam a pagar, como um castigo, na desigualdade socialmente construída. É isto justo?

\section{A propósito de Novas Cartas Portuguesas, tratemos de JUSTIÇA.}

Princípio básico da justiça é o de que só deve haver castigo quando há culpa. 0 sexo com que se nasce não é culpa de ninguém. Mas as mulheres foram e são, em Novas Cartas Portuguesas e, nos nossos dias, em todo o mundo, social e fisicamente punidas sem culpa, em razão do sexo:

- Punidas na identificação primordial com a maternidade.

Possível será ser-se mulher sem se ser fruto? (idem: 33) 
Desejo para a nossa menina todas as riquezas e mil virtudes que em ti reconheci, diferente das outras, no meio deste mundo depravado onde hoje a mulher esquece os seus deveres morais e o seu papel, importante papel de guia dos seus filhos. (idem: 259)

Pois sobre tudo e todas as coisas uma mulher é e será sempre uma mãe. (ibidem)

O Comité de aplicação da Convenção sobre a Eliminação de Todas as Formas de Discriminação contra as Mulheres ${ }^{3}$ sublinha que

[e]m todas as sociedades, as mulheres - que, tradicionalmente, têm desempenhado a sua actividade na esfera privada ou doméstica - têm visto essas actividades serem tratadas como inferiores. Como essas actividades não têm preço para a sobrevivência da sociedade, não pode haver justificação para se lhes aplicarem normas e costumes diversos e discriminatórios (...) [que] impedem as mulheres de dispor de acesso igual aos recursos e de gozar de igual estatuto na família e na sociedade. Mesmo quando existe igualdade na lei, todas as sociedades consagram papéis diversos a homens e a mulheres, sendo os destas considerados inferiores. Assim, estão a ser violados os princípios da justiça

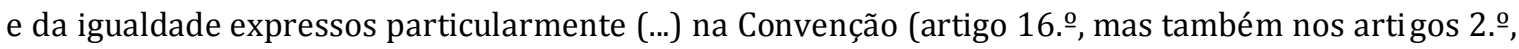
5.ํe 24.ํ). (Comité CEDAW 1994: Recomendação Geral n.ํ21, §11)

\section{- Punidas nos danos colaterais da gravidez.}

Em aventura de amor a dois, é a mulher que depõe e arrisca seu corpo e sua alma, que homem não engravida (...). (Barreno / Horta / Costa 2010: 123)

0 "Índice de Desigualdade de Género"4 do Relatório do Desenvolvimento Humano, 2013 do Programa das Nações Unidas para o Desenvolvimento (PNUD) apresenta como resultados médios a nível mundial no que respeita a "Saúde reprodutiva", uma "Taxa de mortalidade materna", em 2010, de 145 por 100 mil nados vivos, e uma "Taxa de fertilidade adolescente", em 2012, de 51,2 partos por mil raparigas dos 15 aos 19 anos. ${ }^{5} 0$ Comité CEDAW refere também que,

[a]s responsabilidades que as mulheres têm para cuidar e sustentar os filhos afectam o seu direito de acesso à educação, ao emprego e a outras actividades relacionadas com o seu desenvolvimento 
pessoal, e também impõem às mulheres cargas desiguais de trabalho. (Comité CEDAW 1994: Recomendação Geral n.ํㅜ 21, §11)

\section{- Punidas na dominação violenta que sobre elas se abate.}

(...) escândalo de um corpo demasiado próximo da natureza que o homem tenta dominar receando sempre suas vinganças, medo do corpo, corpo de perdição, medo de castração nele, homem erecto e construtor mas a quem só a mulher para os filhos, mulher marginalizada naquilo que o homem rejeita nas suas escolhas pragmáticas, intuição feminina (...), eterno feminino, magia, bruxa, demoníaca, possessa, vampe (ah, mulher que é para te comprar que eu trabalho há séculos, e minhas leis, e tu sempre me foges), corpo que se possui, terra do homem, carne da sua carne, costela de Adão, homem faz-se mãe da mulher para a reorganizar nas suas origens, a partir do caos, mulher poder de tentação e de pacto com a desordem, poder e escândalo, sentimento de culpa do homem, sua crítica marginal, sua imagem negativa (...). (Barreno / Horta / Costa 2010: 81-82)

Porque o homem vai fazendo o mundo e cavando o seu túmulo, e vai chamando a mulher, então dizendo-lhe "mãe", para que esta lhe nomeie o mal e o bem, e lho signifique, e tome em si o absurdo insuportável da ordem das coisas, e vai o homem fazendo o mundo sobre o ventre acolhedor e produtor da mulher, então dizendo-lhe "coisa de mim", e posto na mulher o mal e o bem e o absurdo insuportável da ordem das coisas é então justo que seja ela a primeira vítima (...). (idem: 142)

(...) e ele (...) buscando o mínimo pretexto que lhe permitisse passar ao ataque, à brutalidade, (...) e ele (...) começou a dar-lhe pontapés meticulosamente (...) o seu corpo todo feito numa massa mole, desconhecida, só a si ligada pela dor (...). (idem: 170)

(...) quando o meu pai vem bêbado e bate na minha mãe, grita: aqui eu é que sou o patrão. E ela cala se e põe-se a chorar baixinho. (idem: 228)

Tua não, presa me tens e por tua me tomas em engano da verdade, bem o tentas e bem o sentes e prisioneira sou da tua liberdade (...). (idem: 167)

Um estudo da Organização Mundial de Saúde (WHO 2013) ${ }^{6}$ conclui no sentido de que, em todo o mundo, quase um terço (30\%) de todas as mulheres que estiveram numa 
relação íntima, já sofreram violência física ou sexual por parte do seu parceiro, e de que, globalmente, $38 \%$ de todos os homicídios de mulheres foram cometidos pelo seu parceiro.

Na União Europeia, o inquérito da Agência dos Direitos Fundamentais (FRA 2014)7 realizado em 2012 e publicitado em Março de 2014 concluiu que 1/3 (33\%) das mulheres desde os 15 anos sofreu violência física ou sexual nos 12 meses anteriores à entrevista: 25\% por período superior aos últimos 12 meses; 8\% nos últimos 12 meses.

- Punidas no mundo do trabalho pago.

Monta-se uma indústria de electrónica. Recruta-se mulheres, com os dedos afinados por trabalhos miúdos de costura, renda, e outras artes domésticas ou regiões, com os dedos óptimos para o trabalho miúdo da montagem na electrónica. Paga-se-lhe uma miséria, pois com certeza, são mão-de-obra inqualificada, não têm formação profissional específica para a sua actual função de operárias; é simples explorá-las, elas não sabem que a indústria vai aproveitar de graça uma transferência do seu custo trabalho de dedos, elas não sabem sequer que treinaram seus dedos, é já uma sorte nos seus destinos que alguém lhes aproveite seus dotes minuciosos de mulher, seres sem força, até aí de pouco préstimo que o parir não conta. (Barreno / Horta / Costa: 202-203)

Segundo o já citado Relatório do Desenvolvimento Humano, a "Taxa de participação na força de trabalho", 8 a nível mundial, entre 2006 e 2010, foi de 51,3\% para as mulheres e de $77,2 \%$ para os homens.

Segundo a Organização Internacional do Trabalho (ILO 2009),9 "na maioria dos países, os salários das mulheres situavam-se, em 2009, entre 70 e 90\% dos salários dos homens, com ratios ainda mais baixos em alguns países da Ásia e da América Latina”, e, segundo as Nações Unidas (UNWOMEN/UNIFEM 2008),10 a assimetria salarial a nível mundial era, em 2008/9, de 17\%. No seu Relatório Global sobre Salários 2012/13, a OIT refere que a assimetria salarial em função do género diminuiu, em larga medida porque a situação dos homens piorou com a crise (ILO 2012).

A assimetria construída apenas provocou, objectivamente, injustiça. Uma "injustiça global", como em 2012 sublinhou em Coimbra Ann Stewart, da Faculdade de Direito da 
Universidade de Warwick (Stewart 2012).

Será que a assimetria construída como castigo de uma culpa inexistente veio, ao menos, compensar os homens, resolvendo a assimetria natural? Não. À natureza não se responde com vingança - perde-se sempre... - mas com conhecimento. A assimetria dominadora provocou não só, objectivamente, injustiça, mas o determinismo dos papéis sociais para mulheres e homens, com liberdade limitada, indução à violência, desperdício no desenvolvimento, quebra na coesão social indispensável ao bem-estar generalizado.

Como se demonstra.

O determinismo dos papéis sociais para mulheres e homens prejudica as mulheres.

As tarefas dividem-se em duas espécies: as tarefas do homem e as tarefas da mulher. As tarefas do homem são aquelas da coragem, da força e do mando. (...) Depois há as tarefas das mulheres, que acima de todas está a de ter filhos, guardá-los e tratá-los nas doenças, dar-lhes a educação em casa e o carinho; (...) as mulheres foram feitas para a vida da casa, que é uma tarefa muito bonita e dá muito gosto ter tudo limpo e arrumado para quando chegar o nosso marido ele poder descansar do trabalho do dia que foi tanto, a fim de arranjar dinheiro para nos sustentar e aos filhos. (Barreno / Horta / Costa 2010: 225-226)

Se ao homem compete as grandes e graves decisões do mundo, à mulher compete o glorioso papel de criar os homens que edificarão esse mundo. (idem: 259)

Em matéria de partilha no processo de decisão política, a partilha entre homens e mulheres de "Assentos no parlamento nacional"11 foi, a nível mundial, em 2012 (PNUD 2013), respectivamente de 79,7 e de $20,3 \%, 12$ ou seja, uma assimetria de quase 60 pontos percentuais.

A nível regional (Europa), o "Índice da Igualdade de Género" (EIGE: 2013)13 conclui que, numa escala de 0 a 100 - em que 0 corresponde à desigualdade total e 100 à igualdade total -, a União Europeia apresentava no domínio 'Poder' o resultado mais assimétrico, e por isso o pior, (38) de todas as áreas analisadas.

No que respeita a partilha do tempo de trabalho pago e não pago, o Relatório de Desenvolvimento Humano de 1995 (PNUD 1995) - o ano de Pequim - fez a sua capa com 
figura demonstrativa de que, de todo o trabalho produzido no mundo, os homens realizavam três quartos do trabalho pago e as mulheres dois terços do trabalho não pago.

$\mathrm{Na}$ última estatística global das Nações Unidas sobre a situação das mulheres (UN 2010), evidencia-se, com base em inquéritos sobre os usos do tempo, que, em todas as regiões do mundo, as mulheres dedicam muito mais tempo ao trabalho doméstico do que os homens. Assim,

nas regiões mais desenvolvidas, as mulheres gastam em média quase 5 horas por dia em trabalho doméstico, enquanto os homens gastam em média neste trabalho menos de duas horas e meia, ou seja metade do tempo dedicado pelas mulheres. Em alguns países (incluindo Portugal) a diferença ainda é maior, com as mulheres a multiplicarem por 3 a 4 vezes o tempo gasto pelos homens. Apesar de muito longe de uma situação equilibrada, a partilha entre homens e mulheres de tarefas domésticas é mais favorável nas regiões mais desenvolvidas em comparação com as outras (há países aonde os homens gastam menos de 1/5 do tempo que as mulheres lhes dedicam). A demonstração relativa à América Latina e a África é mais fraca já que só há estatística disponível em poucos países. Mas mesmo os dados pertinentes evidenciam que, nessas duas regiões, as mulheres ocupam em trabalho doméstico não pago muito mais do que o dobro do tempo que os homens gastam. (UN 2010: 100)

Também no âmbito da OCDE - que, pelo menos, desde o início dos anos 90 do século passado, se vem dedicando a este tema - foram realizados estudos que demonstram que "em todo o mundo as mulheres realizam mais trabalho não pago do que os homens" (Miranda 2011: 4), concluindo no sentido de que (OCDE 2012: 199),

- As mulheres realizam mais trabalho não pago do que os homens em todos os países e a assimetria de género aumenta com à chegada de crianças;

- 0 trabalho doméstico tem efeitos negativos na didponibilidade de horas para o trabalho pago e na assimetria salarial;

- Encorajar os pais [homens] a usar melhor as possibilidades das licenças parentais, o emprego a tempo parcial e outras formas flexíveis de trabalho [pago] pode contribuir para uma partilha mais equilibrada do trabalho [pago] e do [de] cuidado.

Na União Europeia, o já referido “Índice da Igualdade de Género" conclui que, o 
domínio 'Tempo' apresenta o segundo pior resultado $(38,8)$ logo a seguir a 'Poder' , a marcar bem a persistência dos estereótipos de género, tanto na chamada esfera pública, como na privada.

O determinismo dos papéis sociais para mulheres e homens prejudica os homens.

Promovendo a Declaração e a Plataforma de Pequim, as Nações Unidas, no âmbito de estudo publicado em 2008 (UNWomen 2008), referem os seguintes custos para os homens: “(...) supressão das emoções para permanecerem 'no controlo'; ausência de relações de cuidado face às crianças; exposição a diversos riscos de saúde, estreitamento de oportunidades de educação; danos nas relações interpessoais com mulheres" qualquer que seja o seu laço familiar ou social com elas, e cuja qualidade determina a qualidade de vida dos homens (UNWomen 2008: 5). Mas também maior exposição à pobreza por menor rendimento na família, se as mulheres não tiverem trabalho pago, "menor esperança de vida, morte prematura por acidente, homicídio e suicídio; taxas mais elevadas de acidentes de trabalho (...), níveis mais elevados de abuso de álcool e tabaco", "[r]elutância na procura de cuidados de saúde" (idem: 6), "sentimento (...) de que foram dados muitos direitos [às mulheres quando são] mães” (idem: 8), "marginalização na família” (idem: 21).

Em estudo publicado em finais de 2012 pela Comissão Europeia ${ }^{14}$ (EC 2012), evidencia-se como prejuízo para os homens o facto de estes desenvolverem actividade profissional durante mais horas do que quereriam, estarem muito tempo ausentes das suas famílias, morrerem, em média, 6 anos antes das mulheres, poderem não encontrar ajuda específica se forem vítimas de violência. Acresce o stress, os riscos de saúde, as relações familiares enfraquecidas (EC 2012: 197).

E eu acrescento, que a privação de liberdade por prisão efectiva revela uma das mais elevadas assimetrias de género em desfavor dos homens a nível mundial: 91,10\%, representando os homens 95,55\% do total e as mulheres cerca de 4,45\% (Walmsey 2012). Em Portugal, em 2012, a assimetria de género era de 88,8\%, sendo a proporção de 5,6\% de mulheres e 94,4\% de homens (INE 2012).

O determinismo dos papéis sociais para mulheres e homens prejudica a sociedade: 
(...) na relação a dois, homem e mulher julgando-se sós e nos seus sexos, se vem imiscuir o que a sociedade fez e exige de cada um. (Barreno / Horta / Costa 2010: 78-80)

E às vezes um pouco como desterradas nos sentimos; se sente a mulher quando não cumpre a figura imposta pelos tempos, não a interpreta e assim tenha de procurar caminhos, outros «países» onde viva em diferença do seu, país dado pelo útero da mãe. (idem: 102)

A repressão perfeita é a que não é sentida por quem a sofre, a que é assumida, ao longo duma sábia educação, por tal forma que os mecanismos da repressão passam a estar no próprio indivíduo, e que este retira daí as suas próprias satisfações. (idem: 198-9)

Ou seja, são os papéis de género uma das formas da repressão perfeita, que não pode ser protegida, porque num Estado de Direito Democrático não se concebe a protecção da liberdade de reprimir, que é incompatível com a liberdade individual das pessoas manipuladas e condicionadas. E, no entanto, "Regra é justiça; por isso me neguei à injustiça" (idem: 143).

Segundo as Nações Unidas, justiça de género implica acabar com as desigualdades entre mulheres e homens que são produzidas e reproduzidas pela família, pela comunidade, pelo mercado e pelo Estado (UNWOMEN/UNIFEM 2010).

Para além dos conhecidos argumentos de natureza económica, que aqui não repetirei, a sociedade é prejudicada na interiorização dos seus fundamentos pelo enviesamento generalizado da percepção de justiça, como demonstra, designadamente, Anália Torres, em estudo que revela o consenso alargado de mulheres (78\%) e de homens $(93,8 \%)$ relativamente a ser "justa" ou "muito justa" a sobrecarga de trabalho que as mulheres suportam face aos homens, no conjunto do trabalho profissional e do trabalho de apoio à vida familiar (Torres 2004: 126-7).

"Mas (...) o que podem as palavras?" (Barreno / Horta / Costa 2010: 197).

E eu pergunto: 0 que pode o direito, como palavra-poder?

\section{A propósito de Novas Cartas Portuguesas, tratemos de DIREITO.}

Apreciemos três aspectos. A opressão na lei pelo Estado patriarcal autoritário, os 
progressos na ordem jurídica - internacional e nos Estados - e o muito que ainda falta.

A opressão na lei pelo Estado patriarcal autoritário corresponde ao tempo de Novas Cartas, que persiste, como então, em muitos lugares no mundo.

Frágeis, inaptas por obrigação, por casta, obedientes por lei a seus donos (...) Em nós nada mandamos e de nós nada decidimos, os desejos vergando aos de nossos pais que nos ordenam ou de nossos maridos que nos compram (...). (idem: 135)

Que infelizes, minha amiga, ambas amarradas por leis tão desumanas que tornam a mulher pertença sempre de alguém, domínio, terra onde se pernoita e semeia. (idem: 145)

(...) proscrita só eu, que só a mulher é irredimível na sua desonra, mulher em si tão pouco conta, mas por estar escrito na lei que sua desonra é a dos machos que deviam tê-la e não souberam guarda-la, consentindo assim numa ameaça à sua propriedade privada, desonra que só é lavável com o sangue da mulher rebelde. (idem: 123)

Ao vos conquistar aniquilaria nesse homem o orgulho destruindo-lhe a honra que muito mais que a vida sempre prezou e mesmo muito mais que a vós (...). (idem: 183)

Mas são inegáveis os progressos na ordem jurídica, internacional e nos Estados. Com efeito, na sequência das habitualmente designadas 'grandes guerras' do Séc. XX, a comunidade internacional aprovou diversos instrumentos jurídicos que, a nível global, reconhecem e preconizam a igualdade de homens e mulheres, ${ }^{15}$ e, em numerosos Estados vigoram leis mais consentâneas com a igual dignidade de todas as pessoas. Mas é também um facto que toda esta normatividade jurídica não foi suficiente para alterar a normatividade social - incluindo a dos poderes de facto - que, ao insistir ainda no dogmatismo autoritário dos papéis sociais de género, impede a igualdade efectiva de mulheres e homens.

É corrente ouvir dizer que a 'mudança de mentalidades' necessária à abolição da normatividade social limitadora 'não se faz por decreto', com isso significando que o Direito terá esgotado a sua intervenção sobre a matéria.

Recordo a discordância de Maria Isabel Barreno: 
Enquanto se disser que as imagens da mulher, ou do feminino, são apenas questão de "mentalidades", e não se lhe reconhecer nenhuma razão pragmática, infra-estrutural - ou seja, a de obrigar as mulheres a cumprirem as suas funções específicas, dentro de determinados moldes, que são os economicamente convenientes para a sociedade; enquanto a dupla tarefa, tal como se processa, for coisa irremediável - por ser "natural", vinda da específica biologia da mulher; por provir de "mentalidades", ou seja, opiniões, e não existir assim argumento decisivo, nada será modificado, a não ser na lenta negociação individual, sujeita às crises do social. (Barreno 1985: 40)

Faço também meu o seu discordar. Já sabemos que o mesmo direito que fez desigualdade e submissão pôde fazer, pelo menos em princípio, igualdade e libertação. Em Portugal, são exemplos importantes o Direito da Família após 1978, os direitos da paternidade após 1999 ou a chamada 'paridade' no acesso a cargos políticos, em 2006. Mas o Direito ainda tem muito para fazer.

Por um lado, tem que se precaver de tentativas de retrocesso disfarçado de modernidade, como a pretensa confusão entre sexo como factor de discriminação e desigualdade estrutural de homens e mulheres sobre a qual é construída a organização social. É que, embora ainda apenas no discurso, há muito quem considere a desigualdade de homens e mulheres como um mero factor de discriminação entre outros, com o argumento de que todas as discriminações são equivalentes e transversais. O que não só vai contra a recente evolução de normas jurídicas fundamentais - que, formal ou simbolicamente, já ultrapassaram a fase de adopção exclusiva das tradicionais cláusulas de não discriminação, para obrigarem também a medidas proactivas, a fim de se atingir, de facto, a igualdade de homens e mulheres ${ }^{16}$ - mas também se funda, quanto a mim, na tentativa de equiparar os efeitos para evitar 'desenraizar' as causas, desviando as atenções da centralidade de uma matéria que diz respeito a toda a humanidade - a desigualdade estrutural de homens e mulheres - e não só a grupos desempoderados ou oprimidos - os compostos por pessoas discriminadas, designadamente, em função da origem, da 'raça', da origem 'étnica', da religião ou crença, da idade, da orientação sexual, da situação de deficiência - aliás, quase sempre, compostos por homens e mulheres. 0 que não ofende, antes reforça, a defesa da 


\section{discriminação múltipla ou intersecionalidade.}

Bem sei que a revolta da mulher é a que leva à convulsão em todos os extractos sociais; nada fica de pé, nem relações de classe, nem de grupo, nem individuais, toda a repressão terá de ser desenraizada, e a primeira repressão, aquela em que veio assentar toda a história do género humano, criando o modelo e os mitos de outras repressões, é a do homem contra a mulher. Nenhum equilíbrio anterior nos será possível, portanto, a partir daí, nem sequer o de manipularmos nossos filhos. (Barreno / Horta / Costa 2010: 198)

A tentativa de retrocesso é a persistência em contrariar a lei nova mantendo este assunto como um tema só ou principalmente de mulheres-enquanto-minoria ou mulheresenquanto-especificidade para evitar a mudança estrutural da organização social e a paridade de homens e mulheres em todas as esferas da vida. Afinal, o pressuposto da cidadania plena de todas as pessoas finalmente "livres e iguais em dignidade e direitos". ${ }^{17}$

(...) e enquanto não houver máquina de fazer filhos é a mulher quem os faz e o problema não será só de capataz ou patrão, mas o de uma sociedade ser também construída a partir disto, do significado do trabalho e de quem o faz - se resistente é a economia e a política, mais é tudo o que as sustém. (Barreno / Horta / Costa 2010: 81)

Depois que foram bifurcados, irremediavelmente, os destinos do homem e da mulher (...) sobre a mulher veio cair, além de todas as angústias vivenciais e de todas as repressões sociais que são comuns ao homem e à mulher, sobre a mulher veio cair a angústia do seu destino biológico, feito drama seu e não mais experiência dramática da espécie, e veio cair a repressão de que esse seu destino biológico feito drama individual é instrumento. (idem: 205)

(...) quem tem medo do ataque aos meios de produção, do ataque aos grupos de poder ou de pressão? Os poucos atingidos. No entanto, mulher todos "têm". POR ISSO, não há problema da mulher, olha que disparate, não é isso que está em causa. (idem: 204)

(...) lembremo-nos, sim, que um negro extremista é já respeitável, mas que uma feminista é vituperada, assustadora do ainda indiscursível, incómoda, ridícula, mesmo para os cavaleiros bem pensantes de toda a libertação (...). (idem: 83) 
Mas o direito tem que se precaver também de equívocos - como o que pretende acrescentar 'a vida pessoal' ou 'a vida privada' à formulação legal "conciliação entre a vida profissional e familiar", como se quem não tem família a cargo devesse beneficiar das acções positivas de quem tem que conjugar estes dois tipos de responsabilidades. Com efeito, à revelia do Direito aplicável ${ }^{18}$ diversas pessoas e instituições - incluindo a Comissão Europeia $^{19}$ e o Governo português ${ }^{20}$ - passaram a designar a conciliação da actividade profissional e da vida familiar, com a inclusão da "vida pessoal" ou da "vida privada". Alega-se que mesmo quem não tem família tem vida pessoal, a qual também deve ser protegida. Mas a desigualdade de homens e mulheres na actividade profissional decorre precisamente da desigualdade de uns e outras no apoio à vida familiar e é dela indissociável. De facto, a questão só se coloca quando o trabalho e o emprego tem que se conciliar com família. A conciliação tem a ver com a divisão equilibrada do trabalho pago e do trabalho não pago de apoio à vida familiar entre as mulheres e os homens. Por isso está no cerne das políticas para a promoção da igualdade entre homens e mulheres que o Direito prevê e por isso exige instrumentos para que o Direito se cumpra.

Também por isso, não se resolve só com equipamentos e serviços externalizáveis, ainda que o Estado assegure que respondem às necessidades e por melhor que seja a sua qualidade.

Admitir que tais medidas são suficientes é aceitar que os homens são dispensáveis e estão dispensados de gastar tempo com a sua família, o que só vem reforçar os velhos estereótipos sobre papéis sociais de género e assim impedir a concretização do direito.

Com efeito, na sequência da constatação de facto de que a maternidade concretizada ou potencial - era o principal factor de discriminação da generalidade das mulheres em matéria de acesso ao trabalho remunerado, ao exercício de uma actividade profissional, à progressão na carreira, à igualdade de remuneração e à participação equilibrada nos processos e decisão - não apenas pela ausência do posto de trabalho por exigências de saúde própria ou da sua criança mas também pela protecção jurídica que progressivamente tem sido conferida à família, para contrariar esse facto e criar condições 
que melhor garantissem a igualdade entre homens e mulheres na esfera pública, foi necessário assegurar juridicamente que também os homens quando são pais tivessem direito a uma protecção, tanto quanto possível equivalente, que os afastasse do posto de trabalho e lhes permitisse a disponibilidade para a família que a normatividade social atribui às mulheres, "pela sua natureza".

Se é a desproporção de tempo de ocupação com a família que prejudica as mulheres na vida profissional, se é o pressuposto cultural de que os homens têm uma disponibilidade integral para a profissão que prejudica e discrimina os homens na vida familiar, são as tarefas da vida familiar que há que repartir entre mulheres e homens para que haja participação equilibrada de uns e outras em todas as esferas da vida. 0 direito à vida pessoal não está aqui em causa.

Não é por causa da vida pessoal que as mulheres são discriminadas na vida profissional. É por causa da vida familiar. Daí a necessidade de as proteger nesse exercício, assegurando, na medida do possível, a partilha desses encargos com os homens, que passam a beneficiar de protecção equivalente. E é a protecção da família, enquanto valor social eminente, que há que acomodar com o direito ao trabalho remunerado de toda e qualquer pessoa, mesmo que tal exija, como exige, ausência do posto de trabalho durante alguns períodos da vida de quem exerce actividade remunerada, com o inerente sacrifício dos direitos de quem seja beneficiário do trabalho daquelas e daqueles que têm família a cargo.

A vida pessoal, a que homens e mulheres têm igual direito, não está sujeita a períodos limitados e exerce-se ao longo de toda a vida activa de toda e qualquer pessoa no tempo livre de responsabilidades profissionais e familiares. Pelo que a repartição entre tempo de trabalho e tempo livre se realiza no âmbito do debate e das negociações sobre tempo para trabalho versus tempo para não trabalho, bem como das normas gerais - e não específicas - sobre a matéria.

Quem não tem família a cargo não tem as mesmas responsabilidades de cuidado de quem a tem e que conduzem a discriminação na vida pública. Não pode ser tratado/a como se a tivesse ou não fosse por ela discriminado. 
Incluir a vida pessoal no âmbito da conciliação/articulação/organização da vida profissional e familiar é subverter o sistema, é neutralizar a protecção à família já reconhecida pelo Direito, que exige do Estado medidas concretas, numa lógica de acção positiva. 0 que não acontece relativamente à vida pessoal - nem tem que acontecer porque ao Estado apenas cabe assegurar o tempo livre de trabalho necessário ao desenvolvimento de todo o ser humano.

Daí que eu considere uma armadilha, para soluções verdadeiramente eficazes, que se misture conciliação com vida privada. Pelo que confunde, pelo que limita o alcance de qualquer medida a tomar, uma vez que as entidades patronais terão que a aplicar a todo/a e qualquer trabalhador/à, e pelo que facilita a desresponsabilização do Estado na matéria, tudo reconduzindo a auto-regulação e a boas práticas, criando novas condições para impedir a concretização da igualdade de género - violando flagrantemente o Direito aplicável - com recurso a argumentos falaciosos.

Só o que é igual deve ter tratamento igual.

O Direito tem que se precaver ainda de pretensas soluções reparadoras, como a abordagem legal da violência de género centrada nas mulheres. Com efeito, o tratamento unilateral - ou quase - dado às mulheres pela legislação internacional e nacional em matéria de violência de género, com enfoque central na vítima e não do agressor, nem em programas globais e vinculativos de eliminação dos fundamentos da desigualdade de género reforça a menorização das mulheres, agora vítimas oficiais muitas vezes em reclusão tutelada, mantém forte potencial para beneficiar o agressor, desvia a atenção da sociedade do facto de os homens ainda serem educados para a dominação, designadamente das mulheres, e vai justificando a ausência ou a timidez de medidas para uma solução estrutural.

Por outro lado, o Direito tem que se libertar dos preconceitos que o tornam insuficiente e do risco, que não quer correr, de ser eficaz.

Sobre isto, também o Direito pode, "no Mundo Globalizado"21, dizer "chega" (Barreno / Horta / Costa 2010: 250). “Onde reeinventar o gesto e a palavra? Tudo está invadido pelos significados antigos (...)" (idem: 199). 
E eu digo: acrescentando aos instrumentos jurídicos globais palavras reinventadas e significados novos que facilitem a concretização da igualdade de mulheres e homens.

Assim, e tendo presente Juan Somavia, o Director-Geral da OIT em 2006, na Conferência Internacional do Trabalho desse ano: "Importa (...) estar ciente de que a chamada produtividade económica é, na realidade, indirectamente subsidiada pela produtividade social do trabalho não remunerado" (Somavia 2006: iv);

recordando as palavras de Ann Stewart:

Há que repensar a relação entre produção (trabalho) e reprodução social (cuidado) (...) Só quando colocarmos o cuidado no coração da sociedade em vez de um mero auxiliar da produção e desenvolvermos quadros legais para apoiar o cuidado, começaremos a enfrentar as injustiças globais de género nos nossos dias; (Stewart 2012)

e considerando também que as medidas a promover, embora não devam ter nem natureza nem expressão simbólicas, deverão agir sobre o simbólico de modo a desconstruir os estereótipos sobre o género, que, em muitos casos, atingem uma dimensão e um dogmatismo de "crença", mais uma vez trago a debate22 um contributo que apela à superação do "medo que todos e todas temos do novo que tudo terá de ser". ${ }^{23}$ E que talvez possa ajudar a construção de "respostas à altura de uma humanidade comum",24 designadamente com o apoio da rede transcultural e internacional visada pelo Projeto "Novas Cartas Portuguesas 40 anos depois".

Vimos que a assimetria natural de poder entre a maternidade certa e a paternidade incerta é, em si e até à data, uma inevitabilidade. Mas tal como a medicina, também o Direito pode corrigir a natureza, assumindo, como sintetiza Elisabeth Badinter, o "primado da cultura" (Badinter 2003: 53).

O Direito pode reforçar o estatuto jurídico da paternidade, inclusivamente através de acções positivas, tornando-a, em todo o mundo e perante a sociedade, uma coisa própria de homens.

0 trabalho de cuidado não remunerado de apoio à vida familiar tem sido uma obrigação social desproporcionada das mulheres. O Direito pode torna-la uma obrigação 
jurídica igualmente repartida entre mulheres e homens, reforçando o poder destes na esfera privada.

A participação e o poder na esfera pública têm pertencido maioritariamente aos homens. 0 Direito pode tornar obrigatória a repartição entre mulheres e homens, quer na participação quer no exercício.

Os homens são educados para a violência e, paradoxalmente, punidos por ela quando a usam. O Direito pode tornar obrigatória a educação para a paz e valorizar os comportamentos de coesão.

E como à injustiça global se responde com instrumentos para a justiça global, importa, em minha opinião, agir pragmaticamente, aperfeiçoando o que existe e criando o que faz falta.

Ou seja, intervir no sistema internacional dos Direitos Fundamentais, bem como nos respectivos sistemas regionais e nacionais.

Assim, por um lado, há que reconhecer através de Protocolos Adicionais aos Pactos das Nações Unidas ${ }^{25}$ e às Convenções e Tratados regionais pertinentes, ${ }^{26}$ bem como, através das adequadas inclusões nas Constituições dos Estados, os seguintes novos direitos fundamentais com a mesma protecção jurídica dos direitos, liberdades e garantias:

- Direito fundamental à não discriminação em função do sexo e à igualdade de homens e mulheres nos vários domínios da vida. Incluindo a saúde, a educação, a participação efectiva tanto no poder político, económico e social, como no poder na esfera privada e familiar, o que abrange a repartição paritária do trabalho de cuidado de dependentes e do trabalho doméstico não remunerado. E ficando o Estado vinculado a assegurar a respectiva concretização, designadamente através de acções positivas que abranjam limiares de paridade para a eliminação das assimetrias que prejudicam as mulheres e das que prejudicam os homens e são evidenciadas, designadamente, pelos resultados do desenvolvimento humano;

- Direito fundamental à protecção da paternidade tal como é reconhecido à 
maternidade, designadamente na conjugação com a actividade profissional, incluindo a participação paritária de homens e mulheres no desenvolvimento e educação de filhas e filhos, bem como no exercício das responsabilidades familiares;

- Direito fundamental ao cuidado, associado ao dever fundamental de cuidar incumbindo paritariamente a homens e a mulheres;

- Direito fundamental à eliminação das causas sistémicas da violência, incluindo a de género.

Por outro lado, haverá que operacionalizar estes novos direitos fundamentais através de duas novas Convenções: uma das Nações Unidas e outra da Organização Internacional do Trabalho.

A Convenção das Nações Unidas sobre o Cuidado e a Eliminação de Todas as Formas de Violência, incluindo a de Género, perpetrada tanto contra mulheres e raparigas, como contra homens e rapazes. Esta Convenção deverá:

- reconhecer o valor económico e o valor social eminentes do trabalho de cuidado, concretizando esse valor de modo a neutralizar a inferioridade de estatuto a que se associa; ${ }^{27}$

- determinar a obrigatoriedade da educação e da formação para a Paz e para o exercício dos direitos e deveres fundamentais, desconstruindo a identificação efectiva do universal com o masculino, anulando a 'diferença hierárquica' entre os sexos e o enviesamento na percepção da justiça e fornecendo conhecimentos e promovendo competências para a autonomia individual, tanto na esfera privada como na esfera pública;

- adequar as molduras sancionatórias e a recuperação das pessoas agressoras à natureza e às motivações do tipo de violência de que se trate; 
- vincular os Estados ao cumprimento de metas, calendários de execução e sanções verdadeiramente dissuasoras para o incumprimento.

A Convenção da Organização Internacional do Trabalho seria sobre a Protecção da Paternidade. Deverá conferir aos homens direitos equivalentes aos que a Convenção sobre a Protecção da Maternidade ${ }^{28}$ confere às mulheres, e abranger a participação equilibrada dos pais trabalhadores no trabalho de cuidado e de apoio à vida familiar. ${ }^{29}$

Nos Estados membros da União Europeia, será ainda necessário proteger a paternidade e os seus direitos através de uma directiva, nova ou revista.

\section{Conclusão}

Nesta época de crise da natalidade em muitos países, é tempo de a comunidade internacional assumir consequentemente as suas responsabilidades, e dirigir aos homens medidas de acção positiva valorizadoras da paternidade, também na actividade económica, entre os pares e na sociedade. Medidas que lhes atribuam um papel indispensável no cuidado de filhos e filhas, que os liguem simbolicamente, obrigatoriamente e de facto à reprodução social. Medidas que os compensem, face às mulheres, do poder natural da maternidade certa, que as tem mantido tuteladas, ciosas de um destino que lhes ensinaram ser inevitável, e aparentemente conformadas com o preço a pagar, apesar de mais ou menos visivelmente insatisfeitas. Medidas que dêem aos homens segurança e tranquilidade, e, assim, os dispensem do fardo de violência, de apropriação, de protecção e de representação da espécie em que foram educados e construíram o mundo para garantir a imortalidade (Cunha Rêgo 2012). Medidas capazes de aprofundar o Estado de Direito Democrático pela vontade política sincera de governantes que entendam o mundo como um lugar em que o primado da razão, da justiça e do respeito da igual dignidade das mulheres e dos homens seja o melhor instrumento, a nível global, para assegurar e sustentar o equilíbrio no desenvolvimento, o bem-estar geral, e uma paz feliz para a humanidade (Cunha Rêgo 2014). 


\section{NOTAS}

${ }^{1}$ Declaração e Plataforma de Acção de Pequim, aprovadas na IV Conferência Mundial sobre as Mulheres, em Setembro de 1995. Vide Estratégias Internacionais para a Igualdade de Género - A Plataforma de Acção de Pequim (1995-2005) (2005).

${ }^{2}$ Os conceitos de sexo e de género que uso são os que, respetivamente, decorrem da doutrina da Organização Mundial de Saúde - OMS, nos termos da qual "Sexo" se refere às características biológicas e fisiológicas que definem mulheres e homens, ${ }^{2}$ e do artigo 3. ${ }^{\circ}$ alínea c) da Convenção do Conselho da Europa para a Prevenção e o Combate à Violência Contra as Mulheres e a Violência Doméstica (também designada como Convenção de Istambul), ${ }^{2}$ nos termos do qual "Género se refere aos papéis, aos comportamentos, às atividades e aos atributos socialmente construídos que uma determinada sociedade considera serem adequados para mulheres e homens".

3 Tendo em conta o contexto do Colóquio Internacional Novas Cartas, Novas Cartografias, Re-Configurando Diferenças no Mundo Globalizado, a maioria das referências é feita na perspectiva mundial.

${ }^{4}$ Medida compósita que reflete a desigualdade de realizações entre mulheres e homens em três dimensões: saúde reprodutiva, capacitação e mercado de trabalho. Para mais desenvolvimentos, ver Nota técnica 3 em <http://hdr.undp.org/en/media/HDR_2013_EN_TechNotes.pdf>) (nota do relatório).

${ }^{5}$ O Relatório Mundial sobre a População de 2013 escolheu como tema "A gravidez na adolescência".

${ }^{6}$ Em Inglês, World Health Organization (WHO).

${ }^{7}$ Em Inglês, Fundamental Rights Agency (FRA).

${ }^{8}$ Proporção da população em idade activa de um país que se envolve no mercado de trabalho, seja a trabalhar ou a procurar activamente trabalho, expressa como percentagem da população em idade activa (nota do relatório).

${ }^{9}$ Em Inglês, International Labour Organization (ILO).

${ }^{10}$ Em julho de 2010, a Assembleia Geral das Nações Unidas criou a UN Women, a Entidade das Nações Unidas para a Igualdade de Género e para o Empoderamento das Mulheres, a qual passou a englobar diversos departamentos das Nações Unidas com atribuições sobre a matéria, designadamente a UNIFEM (Fundo de Desenvolvimento das Nações Unidas para as Mulheres). Daí que as publicações anteriores à criação da UN Women mas editadas por qualquer dos departamentos abrangidos na fusão devam ser referenciadas também com a sigla UNWOMEN.

${ }^{11}$ Proporção de assentos detidos por mulheres - e também por homens - numa câmara baixa ou única ou numa câmara alta ou senado, expressa como percentagem dos assentos totais (nota adaptada do relatório). 
12 UN Women refere 20,9\%, em 1-7-2013.

13 Medida da igualdade de género para a União Europeia. Novo instrumento disponibilizado em 2013 pelo European Institute for Gender Equality, EIGE, [Instituto Europeu para a Igualdade de Género, IEIG] que analisa seis domínios para os quais há dados fiáveis e comparáveis relativamente a todos os Estados membros da União Europeia, a saber 'Trabalho', 'Dinheiro', 'Conhecimento', 'Tempo', 'Poder' e 'Saúde'. A média destes domínios corrresponde a 50,4, variando a posição de cada Estado membro entre 74,3 (Suécia) e 35,3 (Roménia).

${ }^{14}$ Em inglês, European Commission (EC).

15 Na página eletrónica do Gabinete de Documentação e Direito Comparado da Procuradoria-Geral da República - <http://direitoshumanos.gddc.pt/3_1/IIIPAG3_1.htm> e <http://direitoshumanos.gddc.pt/ 3_4/IIIPAG3_4.htm>) - podem encontrar-se muitos desses instrumentos bem como as ligações para as instituições internacionais pertinentes. Relativamente ao Direito da União Europeia, vide <http://ec.europa.eu/justice/gender-equality/rights/index_en.htm> e <http://ec.europa.eu/justice/genderequality/law/index_en.htm>.

16 Designadamente: Tratado da União Europeia <http://eur-lex.europa.eu/collection/eu-law/treatiesforce.html?locale=pt\#new-2-51>

\section{Artigo 2. $\stackrel{\circ}{ }$}

A União funda-se nos valores do respeito pela dignidade humana, da liberdade, da democracia, da igualdade, do Estado de direito e do respeito pelos direitos do Homem, incluindo os direitos das pessoas pertencentes a minorias. Estes valores são comuns aos Estados-Membros, numa sociedade caracterizada pelo pluralismo, a não discriminação, a tolerância, a justiça, a solidariedade e a igualdade entre homens e mulheres.

\section{Tratado sobre o Funcionamento da União Europeia <idem >}

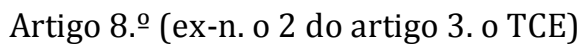

Na realização de todas as suas acções, a União terá por objectivo eliminar as desigualdades e promover a igualdade entre homens e mulheres.

\section{Carta dos Direitos Fundamentais da União Europeia <idem>}

Artigo 23. - - Igualdade entre homens e mulheres

Deve ser garantida a igualdade entre homens e mulheres em todos os domínios, incluindo em matéria de emprego, trabalho e remuneração. 
O princípio da igualdade não obsta a que se mantenham ou adoptem medidas que prevejam regalias específicas a favor do sexo sub-representado.

Decisão n.o 771/2006/CE do Parlamento Europeu e do Conselho, de 17 de Maio de 2006, que institui o Ano Europeu da Igualdade de Oportunidades para Todos (2007) - Para uma Sociedade Justa <http://eur-lex.europa.eu/LexUriServ/LexUriServ.do?uri=CELEX:32006D0771:PT:NOT>

Artigo 4. ํㅡㄹ Integração da igualdade dos géneros

O Ano Europeu deve tomar em consideração as diferentes formas como as mulheres e os homens sofrem a discriminação por razões de origem racial ou étnica, religião ou crença, deficiência, idade ou orientação sexual.

Resolução do Conselho sobre o seguimento do Ano Europeu da Igualdade de Oportunidades para Todos (2007), <http://www.cite.gov.pt/imgs/resolucs/Res_seg_Ano_Eur_Iguald_Oport_2007.pdf>

N. 5 É essencial que as acções que combatem a discriminação em razão da raça ou origem étnica, da religião ou crença, da deficiência, da idade e da orientação sexual atendam às diferenças na forma como homens e mulheres são discriminados;

\section{e Constituição da República Portuguesa}

<http://www.parlamento.pt/Legislacao/Paginas/ConstituicaoRepublicaPortuguesa.aspx >

Artigo 9.. - Tarefas fundamentais do Estado

São tarefas fundamentais do Estado: h) Promover a igualdade entre homens e mulheres.

17 Declaração Universal dos Direitos Humanos <http://www.gddc.pt/direitos-humanos/textosinternacionais-dh/tidhuniversais/cidh-dudh.html>

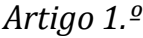

Todos os seres humanos nascem livres e iguais em dignidade e em direitos. Dotados de razão e de consciência, devem agir uns para com os outros em espírito de fraternidade.

${ }^{18}$ Convenção 156 da OIT, relativa à igualdade de oportunidades e tratamento para os trabalhadores dos dois sexos: trabalhadores com responsabilidades familiars <http://www.gddc.pt/direitoshumanos/textos-internacionais-dh/tidhuniversais/emp-conv-oit-156.html>

Carta Social Europeia <http://direitoshumanos.gddc.pt/3_1/IIIPAG3_1_21.htm> 
Artigo 27. - Direito dos trabalhadores com responsabilidades familiares à igualdade de oportunidades e de tratamento

Com vista a assegurar o exercício efectivo do direito à igualdade de oportunidades e de tratamento entre trabalhadores de ambos os sexos com responsabilidades familiares, e entre estes trabalhadores e os outros trabalhadores, as Partes comprometem-se:

1) A tomar medidas apropriadas:

a) Para permitir aos trabalhadores com responsabilidades familiares entrar e permanecer na vida activa ou regressar a ela após uma ausência devida a essas responsabilidades, incluindo medidas no domínio da orientação e da formação profissionais;

b) Para ter em conta as suas necessidades no que respeita às condições de emprego e à segurança social;

c) Para desenvolver ou promover serviços, públicos ou privados, em particular os serviços de guarda de crianças durante o dia e outras formas de guarda;

2) A prever a possibilidade de cada um dos pais, durante um período posterior à licença de maternidade, obter uma licença parental para acompanhamento de um filho, cuja duração e condições serão fixadas pela legislação nacional, pelas convenções colectivas ou pela prática;

3) A assegurar que as responsabilidades familiares não possam, como tais, constituir motivo válido de despedimento.

Tratado da União Europeia <http://eur-lex.europa.eu/collection/eu-law/treatiesforce.html?locale=pt\#new-2-51>

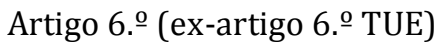

1. A União reconhece os direitos, as liberdades e os princípios enunciados na Carta dos Direitos Fundamentais da União Europeia, de 7 de Dezembro de 2000, com as adaptações que lhe foram introduzidas em 12 de Dezembro de 2007, em Estrasburgo, e que tem o mesmo valor jurídico que os Tratados. (...)

Carta dos Direitos Fundamentais da União Europeia <http://eur-lex.europa.eu/collection/eulaw/treaties-force.html?locale=pt\#new-2-51>

Artigo 33. - Vida familiar e vida profissional

1. É assegurada a protecção da família nos planos jurídico, económico e social. 
2. A fim de poderem conciliar a vida familiar e a vida profissional, todas as pessoas têm direito a protecção contra o despedimento por motivos ligados à maternidade, bem como a uma licença por maternidade paga e a uma licença parental pelo nascimento ou adopção de um filho.

\section{Directiva 2006/54/CE do Parlamento Europeu e do Conselho, de 5 de Julho de 2006, relativa à aplicação do princípio da igualdade de oportunidades e igualdade de tratamento entre homens e mulheres em domínios ligados ao emprego e à actividade profissional (reformulação) \\ <http://www.cite.gov.pt/imgs/directivas/Directiva\%202006-54.pdf> \\ considerando}

(11) Os Estados-Membros deverão, em colaboração com os parceiros sociais, lutar contra o problema das persistentes diferenças salariais em razão do género e contra a segregação em razão do género no mercado de trabalho através de medidas, como disposições flexíveis em matéria de tempo de trabalho, que permitam, tanto aos homens como às mulheres, conciliar mais facilmente a vida familiar e a vida profissional. Tais medidas poderão igualmente incluir disposições adequadas em matéria de licença parental, de que possam beneficiar cada um dos progenitores, bem como a criação de serviços acessíveis e económicos para o acolhimento de crianças e a prestação de cuidados a pessoas dependentes.

(23) Ressalta claramente da jurisprudência do Tribunal de Justiça que qualquer tratamento desfavorável de uma mulher relacionado com a gravidez ou a maternidade constitui uma discriminação sexual directa em razão do sexo. Importa, pois, incluir expressamente este tipo de tratamento na presente directiva.

(24) 0 Tribunal de Justiça tem repetidamente reconhecido a legitimidade, em termos do princípio da igualdade de tratamento, de proteger a condição biológica da mulher na gravidez e na maternidade e de adoptar medidas de protecção da maternidade como meio de atingir uma igualdade concreta. A presente directiva não deverá prejudicar, por conseguinte, a Directiva 92/85/CEE do Conselho, de 19 de Outubro de 1992, relativa à implementação de medidas destinadas a promover a melhoria da segurança e da saúde das trabalhadoras grávidas, puérperas ou lactantes no trabalho. A presente directiva também não deverá prejudicar a Directiva 96/34/CE do Conselho, de 3 de Junho de 1996, relativa ao Acordo-quadro sobre a licença parental, celebrado pela UNICE, CEEP e o ETUC.

(25) Por razões de clareza, é oportuno também consagrar expressamente a protecção dos direitos das mulheres em licença de maternidade no emprego, principalmente no que respeita ao direito de retomar o mesmo posto de trabalho ou um posto de trabalho equivalente, sem qualquer desvantagem nos respectivos termos e condições em resultado do usufruto dessa licença, bem como a beneficiar de quaisquer melhorias nas condições de trabalho a que teriam direito durante a sua ausência. 
(26) Na Resolução do Conselho e dos Ministros do Emprego e da Política Social, reunidos no Conselho de 29 de Junho de 2000, relativa à participação equilibrada das mulheres e dos homens na actividade profissional e na vida familiar, os Estados-Membros foram encorajados a avaliar a possibilidade de as respectivas ordens jurídicas reconhecerem aos trabalhadores do sexo masculino um direito individual e não transferível à licença de paternidade, sem perda dos seus direitos relativamente ao emprego.

(27) Condições similares são aplicáveis à atribuição pelos Estados-Membros, aos trabalhadores do sexo masculino e feminino, de um direito individual e não transferível à licença por adopção. É aos EstadosMembros que compete decidir da atribuição ou não desse direito à licença de paternidade e/ou por adopção e também determinar as eventuais condições, com excepção do despedimento e do regresso ao trabalho, que se inscrevam fora do âmbito da presente directiva.

Artigo 15ํ- Retoma após licença de maternidade

As mulheres que gozem de licença de maternidade têm o direito, após o termo da licença, de retomar o seu posto de trabalho ou um posto de trabalho equivalente em condições que não lhes sejam menos favoráveis, e a beneficiar de quaisquer melhorias nas condições de trabalho a que teriam tido direito durante a sua ausência.

Artigo 16. - Licença de paternidade e por adopção

A presente directiva não prejudica o direito de os Estados-Membros reconhecerem direitos de licença de paternidade e/ou por adopção distintos. Os Estados-Membros que reconheçam esses direitos tomam as medidas necessárias para proteger os trabalhadores do sexo masculino e feminino contra o despedimento durante o exercício desse direito e para garantir que, no fim dessa licença, tenham o direito de retomar o seu posto de trabalho ou um posto de trabalho equivalente em condições que não lhes sejam menos favoráveis e de beneficiar de quaisquer melhorias nas condições de trabalho a que teriam tido direito durante a sua ausência.

Artigo 21. - - Diálogo social

2. Sempre que compatível com as respectivas tradições e práticas nacionais, os Estados-Membros incentivam os parceiros sociais, sem prejuízo da respectiva autonomia, a promover a igualdade entre homens e mulheres, assim como disposições laborais flexíveis, com o objectivo de favorecer a conciliação da vida profissional e familiar, e a celebrar, ao nível apropriado, acordos que estabeleçam regras de combate à discriminação nos domínios referidos no artigo 1.ำ que estejam incluídos no âmbito da negociação colectiva. Estes acordos devem respeitar as disposições da presente directiva e as medidas nacionais de execução pertinentes.

N. 35 - 12/ 2016 | 175-209 - ISSN 1645-1112 | http:/dx.doi.org/10.21747/16451112/litcomp35a10 
Resolução do Conselho e dos Ministros do Emprego e da Política Social, reunidos no Conselho de 29 de Junho de 2000, relativa à participação equilibrada das mulheres e dos homens na actividade profissional e na vida familiar

<http://www.cite.gov.pt/imgs/resolucs/15Resol.pdf>.

\section{Carta comunitária dos direitos sociais fundamentais dos trabalhadores}

<http://ftp.infoeuropa.eurocid.pt/database/000043001-000044000/000043646.pdf>

Igualdade de tratamento entre homens e mulheres

16. Deve ser garantida à igualdade de tratamento entre homens e mulheres. À igualdade de oportunidades entre homens e mulheres deve ser desenvolvida.

Para este efeito, devem intensificar-se, onde necessário, as acções destinadas à garantir à aplicação do princípio da igualdade entre homens e mulheres, nomeadamente no acesso ao emprego, remuneração, protecção social, educação, formação profissional e evolução de carreiras.

Há igualmente que desenvolver medidas que permitam aos homens e às mulheres conciliar as suas obrigações profissionais e familiares.

\section{Constituição da República Portuguesa}

<http://www.parlamento.pt/Legislacao/Paginas/ConstituicaoRepublicaPortuguesa.aspx>

Artigo 59. - - Direitos dos trabalhadores

1. Todos os trabalhadores, sem distinção de idade, sexo, raça, cidadania, território de origem, religião, convicções políticas ou ideológicas, têm direito:

b) A organização do trabalho em condições socialmente dignificantes, de forma a facultar a realização pessoal e a permitir a conciliação da actividade profissional com a vida familiar;

Artigo 67. - Família

2. Incumbe, designadamente, ao Estado para protecção da família:

h) Promover, através da concertação das várias políticas sectoriais, a conciliação da actividade profissional com a vida familiar.

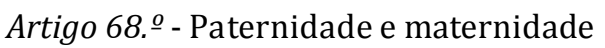

N. 35 - 12/ 2016 | 175-209 - ISSN 1645-1112 | http:/dx.doi.org/10.21747/16451112/litcomp35a10 
1. Os pais e as mães têm direito à protecção da sociedade e do Estado na realização da sua insubstituível acção em relação aos filhos, nomeadamente quanto à sua educação, com garantia de realização profissional e de participação na vida cívica do país.

2. A maternidade e a paternidade constituem valores sociais eminentes.

3. As mulheres têm direito a especial protecção durante a gravidez e após o parto, tendo as mulheres trabalhadoras ainda direito a dispensa do trabalho por período adequado, sem perda da retribuição ou de quaisquer regalias.

4. A lei regula a atribuição às mães e aos pais de direitos de dispensa de trabalho por período adequado, de acordo com os interesses da criança e as necessidades do agregado familiar.

Código do Trabalho <http://www.cite.gov.pt/pt/legis/CodTrab_indice.html> Designadamente:

Artigo 33. $\stackrel{\circ}{\text { Parentalidade }}$

1 - A maternidade e a paternidade constituem valores sociais eminentes.

2 - Os trabalhadores têm direito à protecção da sociedade e do Estado na realização da sua insubstituível acção em relação ao exercício da parentalidade.

e seguintes.

Artigo 212. ${ }^{\circ}$ Elaboração de horário de trabalho

2 - Na elaboração do horário de trabalho, o empregador deve:

b) Facilitar ao trabalhador a conciliação da actividade profissional com a vida familiar;

${ }_{19}$ Por todos, Comunicação ao Parlamento Europeu, ao Conselho, ao Comité Económico e Social Europeu e ao Comité das Regiões Estratégia para a igualdade entre homens e mulheres 2010-2015, COM (2010) 491 final. <http://www.cite.gov.pt/pt/destaques/complementosDestqs/Estrat_iguald_hom_mulh_2010_15.pdf>.

20 Por todos, V Plano para a Igualdade de Género, Cidadania e Não Discriminação, 2014-2017 <http://www.cig.gov.pt/planos-nacionais-areas/cidadania-e-igualdade-de-genero/>.

${ }^{21}$ Da apresentação do Colóquio Internacional Novas Cartas, Novas Cartografias: Re-configurando Diferenças no Mundo Globalizado, Universidade de Évora, 13-15 Março 2014.

${ }^{22}$ Sobre esta questão, ver Cunha Rêgo 2004; 2006; 2009; 2010a; 2010b; 2013.

23 “Tudo terá de ser novo, e todos temos medo." (Barreno / Horta / Costa 2010: 198). 
${ }^{24}$ Apud apresentação do Colóquio Internacional Novas Cartas, Novas Cartografias: Re-configurando Diferenças no Mundo Globalizado, Universidade de Évora, 13-15 Março 2014.

25 Pacto Internacional sobre os Direitos Civis e Políticos < http://direitoshumanos.gddc.pt/3_1/ IIIPAG3_1_6.htm> e Pacto Internacional sobre os Direitos Económicos, Sociais e Culturais <http://direitoshumanos.gddc.pt/3_1/IIIPAG3_1_4.htm>.

${ }^{26}$ Exemplo: para a Região Europa, a Convenção para a Protecção dos Direitos Humanos e das Liberdades Fundamentais <http://direitoshumanos.gddc.pt/3_1/IIIPAG3_1_13.htm>, a Carta Social Europeia Revista $<$ http://direitoshumanos.gddc.pt/3_1/IIIPAG3_1_21.htm>, incluindo a União Europeia: Carta dos Direitos Fundamentais da União Europeia em conexão com o artigo 6.ํ do Tratado da União Europeia.

27 Na sequência, designadamente, da Plataforma de Ação de Pequim e compromissos internacionais posteriores <http://www.un.org/womenwatch/daw/beijing/platform/>, bem como de estudos internacionais e da União Europeia sobre homens e igualdade de género indicados na bibliografia.

${ }^{28}$ A mais recente das Convenções da OIT sobre a protecção da maternidade é a Convenção n.o 183 (2000)

<http://www.ilo.org/dyn/normlex/en/f?p=NORMLEXPUB:12100:0::NO::P12100_LLO_CODE:C183>.

${ }^{29}$ Na sequência do ponto 28 das Conclusões Acordadas na 98. - Sessão da Conferência Internacional do Trabalho, em Junho de 2009, Resolutions adopted by the International Labour Conference at its 98th Session (Geneva, June 2009) p.13-14:

28. [extracto] A legislação e as políticas (como licença por paternidade e/ou parental pagas) que encorajem os homens a participar nas responsabilidades do cuidado, mostraram funcionar em diversos países. 0 comportamento dos homens precisa de mudar, uma vez que as responsabilidades parentais partilhadas são chave para mudar os obstáculos que advêm de estereótipos. Reajustar a divisão de trabalho em casa para uma distribuição equilibrada de tarefas tem benefícios significativos para homens e mulheres.

N. 35 - 12/ 2016 | 175-209 - ISSN 1645-1112 | http:/dx.doi.org/10.21747/16451112/litcomp35a10 


\section{Bibliografia}

Badinter, Elisabeth (2003), La fausse route, Paris, Odile Jacob.

Barreno, Maria Isabel (1985), O Falso Neutro, Lisboa, Instituto de Estudos para o Desenvolvimento, Coleção Educação n. ํ 1, Edições Rolim [edição esgotada].

Barreno, Maria Isabel / Horta, Maria Teresa / Costa, Maria Velho da / Ana Luísa Amaral (org.) (2010), Novas Cartas Portuguesas, Edição Anotada, Lisboa, Dom Quixote [1972].

Comité de aplicação da Convenção sobre a Eliminação de Todas as Formas de Discriminação contra as Mulheres - Comité CEDAW (1994), - Recomendação Geral n.o 21, sobre Igualdade no Casamento e nas Relações Familiares.

Cunha Rêgo, Maria do Céu (2004), "Novas respostas do Direito para a concretização da Igualdade de Género", ex-aequo - Revista da Associação Portuguesa de Estudos sobre as Mulheres n.o 10, Porto, Edições Afrontamento, 83-101.

- - (2006), "Empowerment e Igualdade de Género na revisão a meio percurso da Estratégia de Lisboa Março de 2005”, ex-aequo - Revista da Associação Portuguesa de Estudos sobre as Mulheres n.․ 13, Porto, Edições Afrontamento, 43-58.

- - (2009), A dimensão do Cuidar no espaço do Direito, Comunicação apresentada no Ciclo de Conferências e Comunicações Internacionais "A DIMENSÃO do CUIDAR na re.significação do espaço público - Com Maria de Lourdes Pintasilgo em fundo”, Universidade de Évora, 27 de Junho de 2009.

- - (2010a), A necessidade de alterar as Convenções internacionais para garantir a igualdade efectiva entre mulheres e homens, Comunicação apresentada na Reunião da Federação Internacional das Mulheres de Carreiras Jurídicas, Évora, Conselho Distrital da Ordem dos Advogados, 30 de Abril de 2010.

- - (2010b), “A construção da igualdade de homens e mulheres no trabalho e no emprego na 
lei portuguesa", in Virgínia Ferreira (org.), A Igualdade e Mulheres e Homens no Trabalho e no Emprego em Portugal: Políticas e Circunstâncias, Colecção "Estudos" n.ํㅜ 7, Lisboa, CITE, 57-98.

- - (2010c), "Nos 15 anos da Plataforma de Pequim", Revista de Estudos Demográficos, n.. 47, Lisboa, Instituto Nacional de Estatística, I. P., 21-46.

- - (2012), "Políticas de Igualdade de Género na União Europeia e em Portugal: Influências e incoerências", ex-aequo - Revista da Associação Portuguesa de Estudos sobre as Mulheres n.음 25, Porto, Edições Afrontamento, 29-44.

- - (2013), “(Auto)-retrato: Maria do Céu da Cunha Rêgo”, Faces de Eva - Estudos sobre a Mulher, n.ํㅜ 30, Lisboa, Edições Colibri, 163-170.

- - (2014), Anular a desigualdade de género: a lei pode fazer mais, Texto elaborado a partir de apresentação no Colóquio Internacional: "Direito(s) e Desigualdades" organizado pelo Centro de Estudos Sociais da Faculdade de Economia da Universidade de Coimbra, em 24 de Abril de 2012.

Estratégias Internacionais para a Igualdade de Género - A Plataforma de Acção de Pequim (1995-2005) (2005), Lisboa, Comissão para a Igualdade e para os Direitos das Mulheres.

European Comission (EC) (2012), The Role of Men in Gender Equality - European strategies \& insights < <http://ec.europa.eu/justice/events/role-of-men/index_en.htm>.

European Institute for Gender Equality (EIGE) (2012) Gender Equality Index <http://eige.europa.eu/content/gender-equality-index>.

Fundamental Rights Agency (FRA) (2014) Violência contra as mulheres: um inquérito à escala da União Europeia <http://fra.europa.eu/sites/default/files/fra-2014-vaw-surveymain-results_en.pdf>.

Fundo das Nações Unidas para a População (FNUAP) (2013), Relatório Mundial sobre a População, 2013, <http://www.unfpa.org.br/novo/index.php/669-gravidez-naadolescencia-e-tema-do-relatorio-anual-do-unfpa-2>. 
INE, Dossiê Género. <http://www.ine.pt/xportal/xmain?xpid=INE\&xpgid=ine indicadores\&ind 0 corrCod $=0007340 \&$ contexto=pgi\&selTab=tab10>.

International Labour Organization (ILO) (2009), Global Employment Trends for Women, March 2009. <http://www.ilo.org/global/publications/WCMS_103456/lang--en/ index.htm>.

-- Global Wage Report 2012/13, Gender pay gap drops, but not for the right reasons, 2012/2013. <http://www.ilo.org/global/about-the-ilo/newsroom/news/WCMS_192901/ lang-en/index.htm>.

Miranda, V. (2011), "Cooking, Caring and Volunteering: Unpaid Work Around the World", OECD Social, Employment and Migration Working Papers, No. 116, OECD Publishing. doi: 10.1787/5kghrjm8s142-en <www.oecd.org/berlin/47258230.pdf>.

OECD (2012) Closing the Gender Gap: Act Now <www.oecd.org/gender/ closingthegap.htm>.

Programa das Nações Unidas para o Desenvolvimento (PNUD) (2013), Relatório do Desenvolvimento Humano, 2013. <http://hdr.undp.org/en/content/relatório-dodesenvolvimento-humano-2013-0>.

-- Human Development Report, 1995. <http://hdr.undp.org/en/content/humandevelopment-report-1995>.

Somavia, Juan (2006), "Changing Patterns in the World of Work", Report of the DirectorGeneral, International Labour Conference, 95th Session, Report I (C), International Labour Office, Geneva <http://www.ilo.org/public/english/standards/relm/ilc/ilc95/ reports.htm>.

Stewart, Ann (2012), Global Injustices: a Gendered Perspective, Comunicação apresentada ao Colóquio Internacional: "Direito(s) e Desigualdades" organizado pelo Centro de Estudos Sociais da Faculdade de Economia da Universidade de Coimbra em 24 de Abril de 2012. <http://saladeimprensa.ces.uc.pt/?col=canalces\&id=6696\#.V-91CDJOpPM>. 
Torres, Anália (coord.) (2004), Homens e Mulheres entre Família e Trabalho, Lisboa, CITE. UN (2010), The World's Women 2010 - Trends and Statistics. $<$ http://unstats.un.org/unsd/demographic/products/worldswomen/WW_full\%20report_c olor.pdf>.

UN Women (2008), Women 2000 and Beyond, The Role of Men and Boys in achieving Gender Equality.<http://www.unwomen.org/en/digital-library/publications/2008/12/women2000-and-beyond-the-role-of-men-and-boys-in-achieving-gender-equality\#view> .

UNIFEM, part of UN Women (2008), Progress of the World's Women 2008/2009: Who Answers to Women? Gender and Accountability <http://www.unwomen.org/en/digitallibrary/publications/2008/1/progress-of-the-world-s-women-2008-2009-who-answersto-women>. [em português: http://www2.unwomen.org/ /media/headquarters/ media/publications/unifem/poww08_report_full_text_pt.pdf?v=1\&d=20140917T101016). -- (2010), Gender Justice: Key to Achieving the Millennium Development Goals, <http://www.unwomen.org/en/digital-library/publications/2010/1/gender-justice-keyto-achieving-the-millennium-development-goals>.

Walmsley, Roy (2012), World Female Imprisonment List International Centre for Prison Studies [second edition].

World Health Organization (WHO) (2013), Global and regional estimates of violence against women: prevalence and health effects of intimate partner violence and non-partner sexual

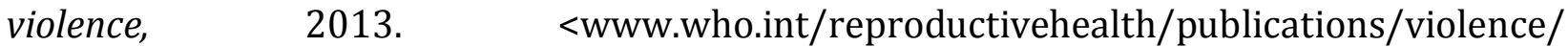
9789241564625/en/index.html>. 
Maria do Céu Cunha Rêgo é jurista e formadora. Natural de Elvas. 65 anos. Casada, 2 filhas, 2 netas, 1 neto. Na área da igualdade de homens e mulheres: é membro do Grupo Técnico Científico do Conselho Consultivo da Comissão para a Cidadania e Igualdade de Género, do Centro Interdisciplinar de Estudos de Género e de várias organizações não-governamentais; é oradora em seminários e iniciativas afins, autora de referenciais de formação e de artigos em revistas da especialidade. Foi representante de Portugal no Conselho de Administração e no Fórum de Peritas/os do Instituto Europeu para a Igualdade de Género, Secretária de Estado para a Igualdade, Presidente da Comissão para a Igualdade no Trabalho e no Emprego e Vice-Presidente da Comissão para a Igualdade e para os Direitos das Mulheres. 